\title{
Physical activity in Dublin children aged 7-9 years
}

\author{
J Hussey, J Gormley, C Bell
}

\begin{abstract}
Objectives-To investigate the amount of regular activity and time spent in sedentary occupations in children aged 7-9 years. Sex differences in levels of activity and time and facilities for physical education at school were also examined.

Methods-A $10 \%$ sample of Dublin

National Schools were selected. Parents of children in second class were surveyed. The questionnaire used was a modification of the Modifiable Activity Questionnaire for Adolescents. Teachers of second class were questioned about the time and facilities for physical education in schools. Results-Some 39\% of children were participating in hard exercise for at least 20 minutes three or more times a week, with fewer girls $(28 \%)$ than boys $(53 \%)$ contributing to this result. A further $57 \%$ of children were engaging in at least 20 minutes of light exercise three or more times a week, with no sex differences. Estimated energy expenditure in regular activity was higher in boys than girls. Most $(78 \%)$ of the children were spending one to three hours a day sedentary in front of a screen. Conclusions-This study provides comprehensive data on physical activity levels in Dublin schoolchildren aged 7-9 years. The amount of inactivity is of concern. Even at this young age, boys are reported to participate in more physical activity than girls.

(Br f Sports Med 2001;35:268-273)
\end{abstract}

Keywords: physical activity; exercise; children

Regular physical activity by adults is associated with a decreased risk of coronary artery disease. ${ }^{1}$ Inactivity in childhood can influence activity patterns in adulthood ${ }^{2}$ and may increase susceptibility to obesity and cardiovascular disorders. ${ }^{34}$ The American College of Sports Medicine ${ }^{5}$ and The National Institute of Health Consensus ${ }^{6}$ advocate an accumulation of at least 30 minutes of moderate intensity physical activity on most days of the week.

A 1989 study of fitness and activity levels in 10-13 year old Irish children found that one third of the sample exercised four or more times a week. ${ }^{7}$ Only $23 \%$ walked or cycled to school. A study in 1998 examining 9-17 year old Irish children found that 53\% exercised four or more times a week. ${ }^{8}$ Boys exercised more than girls, and for both sexes exercise participation decreased with age.

The amount of time spent by children watching television may influence their levels of physical activity. In 1989, Irish children were found to spend a mean of 2.95 hours watching television. ${ }^{7}$ In the United States in 1998, Andersen et al found that $67 \%$ of children aged 8-16 years watched at least two hours of television a day, with $26 \%$ watching more than four hours. Children who watched more than four hours a day had more body fat $(\mathrm{p}<0.001)$ than those who watched less than two hours a day.

Measuring habitual physical activity in children poses many challenges. Methods such as measurement of energy expenditure by determination of oxygen consumption, although accurate, involve equipment (facemask/ mouthpiece) that may interfere with normal activities, and are limited in large studies because of time and expense. The doubly labelled water technique does not restrict activity, but one disadvantage is its high cost. ${ }^{10}$ Recording of heart rate and movement counters are practical alternatives in field settings, but, for very large scale studies in which simple methods are required, questionnaires are commonly used. Younger children have limited information about their activity patterns, and parents or teachers may be questioned about a child's activity.

In contrast with the data on exercise patterns in older children and teenagers, there are few published reports on physical activity in Irish children under 9 years of age. This, coupled with the concern that general physical activity levels are less than they were 20 years ago, led to the initiation of this study, which aimed to determine physical activity levels in 7-9 year old children in Dublin National Schools.

The objectives were to determine:

- the amount of overall activity (duration, frequency, and number of activities);

- the amount of time in sedentary occupations;

- any sex differences in levels of physical activity;

- the time and facilities for physical education $(\mathrm{PE})$ in schools.

\section{Methods}

A list of National primary schools in Dublin was obtained from the Department of Education and Science. The list consisted of 396 schools suitable for inclusion (excluding schools for children with special needs). The schools were then coded by deprivation index into five areas where 1 is the highest (socioeconomically) and 5 is the lowest (SAHRU Technical report). ${ }^{11}$ The Republic of Ireland is divided into 3440 District Electoral Divisions (smallest administrative areas for population statistics), and the indicators used in defining the five areas of deprivation index areas are: unemployment, low social class, no car, rented accommodation, and overcrowding. Schools 
Table 1 Return rates from schools, subject numbers, and mean METs/hour/week in areas 1-5

\begin{tabular}{llllll}
\hline & 1 & 2 & 3 & 4 & 5 \\
\hline Number of schools surveyed & 16 & 8 & 2 & 8 & 3 \\
Mean (range) return rate (\%) & $53(14-94)$ & $41(16-91)$ & $42(40-45)$ & $48(23-93)$ & $38(27-60)$ \\
Number of subjects in study & 473 & 157 & 45 & 82 & 29 \\
Mean METs/hour/week & 36 & 40 & 40 & 42 & 70 \\
\hline
\end{tabular}

are listed according to postal code. To ensure geographical spread, every 10th school was selected from each of the five (deprivation index) areas.

The principal of each selected school was contacted and the aim of the study was explained. Then a copy of the questionnaire and a letter of explanation were sent. If a school declined to participate in the study, the next school on the list within the same area was selected (for areas 1, 2 and 4, three schools declined, for areas 3 and 5, two schools declined). After consent from the school, questionnaires and consent forms for parents were delivered to the school. As it was the parents who were to fill in the questionnaire, they also received a letter of explanation.

The questionnaire was a modification of the Modifiable Activity Questionnaire for Adolescents. ${ }^{12}$ The reproducibility and validity of the original questionnaire was established by Aaron et al. ${ }^{12}$ As the children in this study were much younger than adolescents, it was thought that parents would provide more reliable and accurate information about time spent in physical activity. In the original questionnaire, the first question sought information on the number of times in the preceding two weeks that the child had participated in at least 20 minutes of hard exercise, hard exercise being defined as exercise that resulted in heavy breathing and a fast heart beat. Information on the number of times in the preceding two weeks that the child had participated in at least 20 minutes of light exercise was sought in the second question. Light exercise was defined as exercise that did not result in heavy breathing or a fast heart beat. The third and fourth questions dealt with the number of hours a day spent watching television, videos, or playing computer games and the number of competitive activities in which the child participated.

The final question sought to estimate the energy expended in regular physical activity each week. The parent indicated in which activities the child participated regularly over the preceding year. For each activity, the number of months over the year, the average number of days a week, and the average minutes a day that it was performed were ascertained. The above information was used to calculate the hours a week spent at each activity as follows:

hours a week $=(\mathrm{M} \times(4.3$ weeks $/$ month $) \times$

$$
\mathrm{D} \times \mathrm{N}) /((60 \mathrm{~min} / \mathrm{h})(52 \text { weeks/year }))
$$

where $\mathrm{M}$ is the number of months, $\mathrm{D}$ is the number of days a week, and $\mathrm{N}$ is the number of minutes a day.

Energy expended in regular activities each week - that is, metabolic equivalents (METs)/ hour/week-was determined by multiplying the hours a week spent at each activity by the metabolic cost of each activity in METs (tables in Montoye et $a l^{13}$ ). An arbitrary threshold for minimal METs/hour/week was calculated on the basis of a child exercising for 30 minutes a day for four days of the week (most days) at a moderate intensity (7 METS):

minimal METs/hour/week $=((12 \times 4.3 \times 4 \times$ $30) /(60 \times 52)) \times 7$ METs $=1.98 \times 7 \mathrm{METs}$ $=13.9$ or $14 \mathrm{METs} /$ hour/week.

The modifications to the original questionnaire included the addition of a question on transport to school, and, as these children were under 9 years of age, the question on involvement in competitive activities was removed. Under the past year activities, sports played in Ireland such as Gaelic football, hurling, and rugby were added.

A questionnaire was sent to teachers of the children in second class in the participating schools. The questionnaire for teachers contained questions on the frequency, duration, and location of PE classes during school hours.

DATA ANALYSIS

Data were coded and entered into Excel (Microsoft). Descriptive analysis was performed. $\chi^{2}$ tests were used for comparison of variables between sexes. $t$ tests (unpaired) were used to compare differences between sexes and METs/hour/week and to compare children from different areas and METs/hour/week.

\section{Results}

Thirty seven schools participated in the study. Average return rates from each school ranged from $38 \%$ in area 5 to $53 \%$ in area 1 (table 1 ). However, the number of schools in each area (as coded by the deprivation index) was very different-for example, there were 16 schools in area 1 compared with two schools in area 3. In total, 786 questionnaires were analysed. Of the 786 subjects, 352 were boys and 434 were girls. Eighty six $(11 \%)$ had a medical condition that could interfere with physical activity (74 had asthma).

Some $39 \%$ of children participated in at least 20 minutes of hard exercise three or more times a week; significantly more boys (53\%) than girls $(28 \%)$ contributed to this result $(p<0.001)$ (fig 1A). There were no significant sex differences in the participation in light exercise, with $57 \%$ of children exercising lightly for at least 20 minutes three or more times a week (fig 1B).

An examination of the mode of transport to school showed that $40 \%$ of children ( $44 \%$ boys, $37 \%$ girls) walked to school and $33 \%$ (31\% boys, $35 \%$ girls) were brought to school by car. For $22 \%$ ( $21 \%$ boys, $29 \%$ girls), a combination of walking and being driven to school was reported, and $5 \%$ of children travelled by 

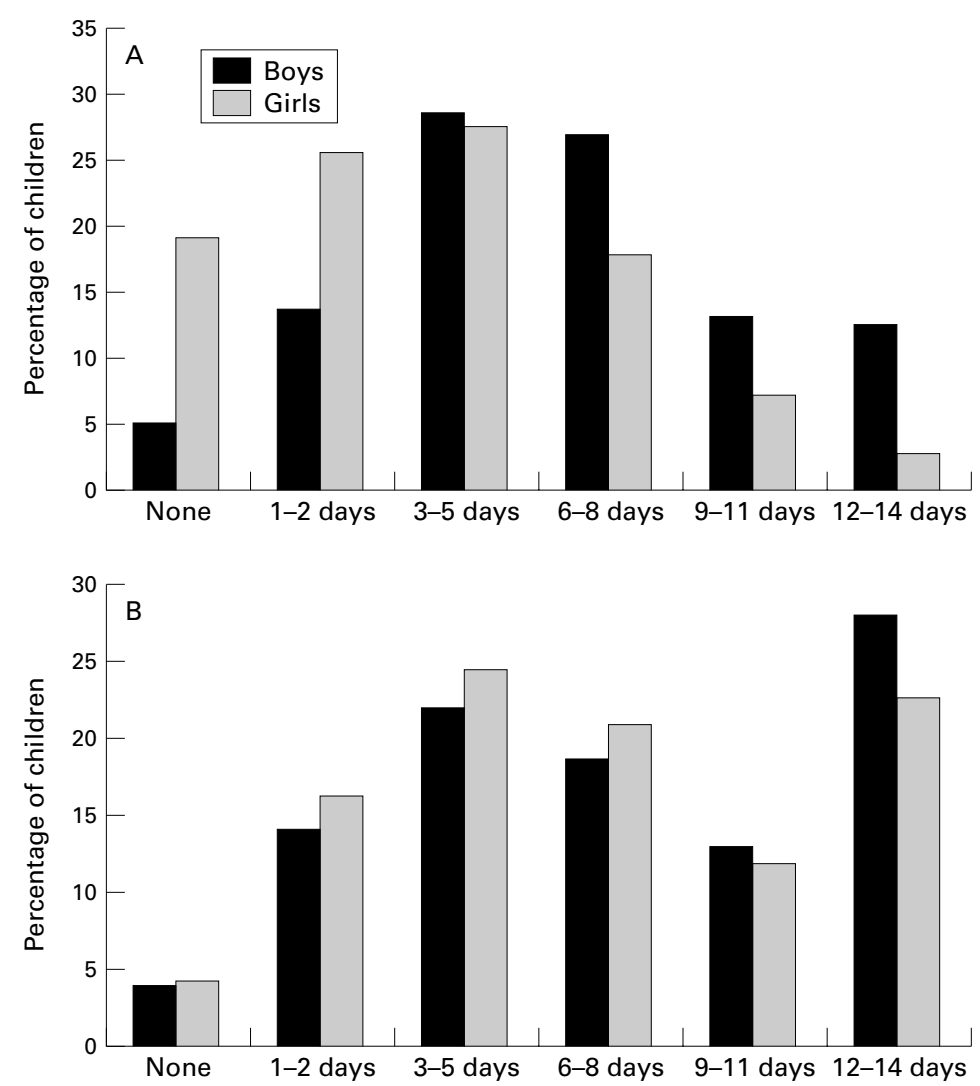

Figure 1 (A) Number of days in the past 14 on which the child spent at least 20 minutes in hard exercise. (B) Number of days in the last 14 on which the child participated in at least 20 minutes of light exercise.
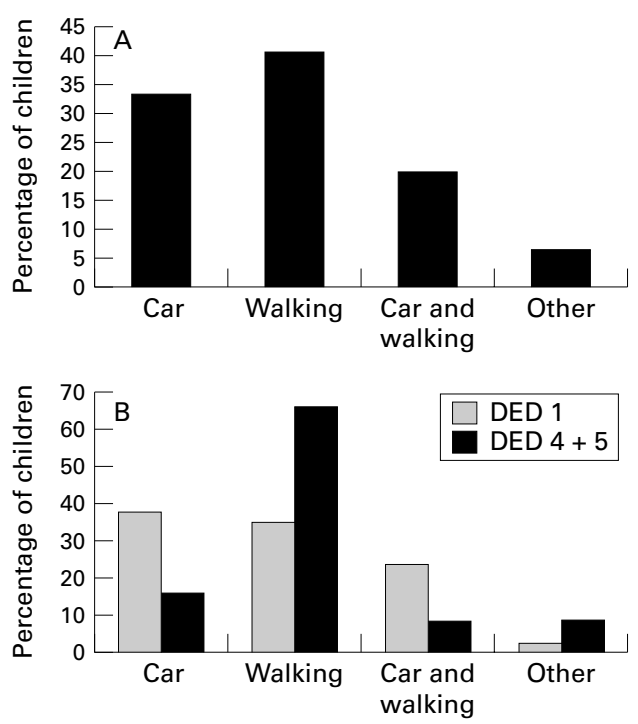

Figure 2 (A) Mode of transport to school. (B)

Comparison of mode of transport to school between lowest and highest deprivation areas (DED, District Electoral Division).

bus (fig $2 \mathrm{~A}$ ). Figure $2 \mathrm{~B}$ shows that $35 \%$ of children in area 1 walked to school compared with $66 \%$ in areas 4 and 5.

Table 2 shows that $60 \%$ of children were spending up to three hours a day in front of a screen, and $18 \%$ were spending more than three hours a day. No sex differences were seen. No differences in the number of hours spent watching television/videos or playing computer games were seen when area 1 was compared
Table 2 Time spent watching television/videos or playing computer games

\begin{tabular}{lcc}
\hline Time (hours a day) & Boys (\%) & Girls (\%) \\
\hline None & 1 & 2 \\
1 hour or less & 19 & 22 \\
$2-3$ hours & 62 & 58 \\
$4-5$ hours & 9 & 13 \\
6 hours or more & 8 & 5
\end{tabular}

Table 3 Time spent watching television/videos or playing computer games: comparison between area 1 and areas 4 and 5

\begin{tabular}{lcc}
\hline Time (hours a day) & Area 1 & Areas 4 and 5 \\
\hline None & 1.5 & 2.6 \\
1 hour or less & 24 & 11.1 \\
2-3 hours & 59.2 & 60.7 \\
$4-5$ hours & 9.9 & 15.4 \\
6 or more & 5.3 & 9.4 \\
\hline
\end{tabular}

Values are percentage of children.

with areas 4 and 5 (table 3). As 14 METs/hour/ week was used as a minimal level of regular activity participation, the number of subjects falling beneath this activity threshold was calculated. Some $14 \%$ of boys and $24 \%$ of girls were reported to engage in less than the minimal recommendation. Overall, boys were expending significantly more energy in regular activities than girls (46 $v 33 \mathrm{METs} /$ hour/week) $(\mathrm{p}<0.001)$. The hours spent watching television/video or playing computer games was compared with energy expended in regular activities (fig 3). Subjects were divided into two groups according to whether they spent more or less than three hours a day sitting in front of a screen, and the leisure time energy expenditures of the two groups were compared for the two sexes; no differences were seen.

Although there were considerable differences in the number of subjects between the five areas, overall activity in areas 4 and 5, as measured by METs/hour/week, was compared with area 1 . Children in areas 4 and 5 expended significantly more energy in regular activity than children in area 1 (45.9 $v 35.8$ METs/ hour/week; $\mathrm{p}<0.005)$.

\section{TEACHERS' RESPONSES}

Sixty eight questionnaires were sent to teachers, and 49 were returned, making a response rate of $72 \%$. Teachers reported that they had one or two PE classes a week (a mean of 1.5). The duration of PE classes was 10-60 minutes. All but one teacher reported that it was obligatory to participate in the class. The location of the classes varied, often depending on the

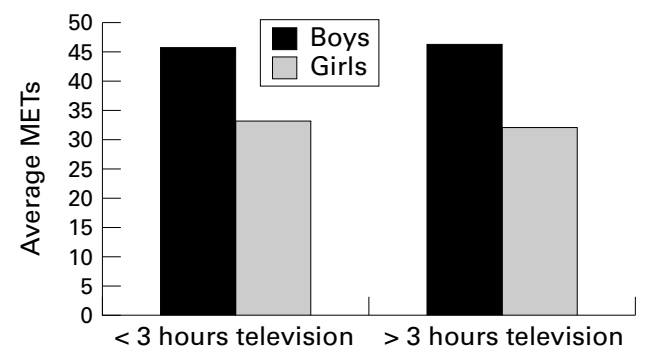

Figure 3 Average METs for boys and girls watching less than three hours of television and those watching more than three hours of television. 
weather, but all had a gym or hall for PE sessions. The mean length of time per session that children were reported to spend in vigorous activity was 15 minutes (range 5-45). Where appropriate, boys and girls did the same activities.

\section{Discussion}

The topic of physical activity in children has received much attention in recent years. This study differs from many others in that it examines physical activity levels in children from differing socioeconomic groups.

\section{RETURN RATES}

The return rates of the questionnaires ranged from a mean of $38 \%$ in area 5 to a mean of $53 \%$ in area 1 but within these the ranges were large. As the number of schools in each area differed and an overall $10 \%$ sample was selected, the number of subjects ranged from 473 in area 1 to 29 in area 5 . With such small numbers in some areas, it was difficult to compare data acquired with respect to differences in socioeconomic status. Because of the very low response rate in area 5 , it is possible that the results from this area may not be totally representative. Principals in some schools commented that literacy or language problems could have influenced the response rate. It was not possible to chase up non-responders because it was the headmaster/teachers who were responsible for the circulation and collection of questionnaires.

\section{PARTICIPATION IN HARD EXERCISE}

It was found that $39 \%$ of children were participating in hard exercise for at least 20 minutes three or more times a week. This figure is low compared with the figure of 53\% reported for an older age group (9-17 years) who exercised four or more times a week. ${ }^{8}$ However, the fact that a premise of at least 20 minutes was stipulated may be a reason for this lower result. Prolonged exercise may not be the natural choice of younger children for whom activity may be typically intermittent. ${ }^{14}$ Fewer girls were participating in hard exercise, and this sex difference was also seen in a recent Irish study in which $45 \%$ of girls compared with $62 \%$ of boys reported exercising four or more times a week. ${ }^{8}$ Sex differences in the amount of vigorous physical activity performed have been reported by others, with girls exercising less than boys of a similar age. ${ }^{14-16}$

\section{TYPE OF ACTIVITIES}

Energy expenditure in regular physical activities was higher in boys, implying that boys participate in more vigorous activities for longer and/or more frequently than girls. Common activities preferred by boys, such as rugby, hurling, and soccer, require on average higher energy expenditure than some more female orientated activities of children of this age such as ballet. It is worrying that $24 \%$ of girls and $14 \%$ of boys are exercising less than the minimal recommendation. This study, however, only addressed regular physical activity and not the intermittent sporadic activity that is naturally seen in children of this age if given the opportunity. There was a difference in energy expended on regular activity between children in areas 4 and 5 combined compared with those in area 1 , but these results may need to be interpreted with some caution because of the difference in numbers and low response rate in area 5.

AMOUNT OF PE DURING SCHOOL HOURS

All schools had either one or two periods of PE a week, with a mean duration of 20-30 minutes. Teachers reported that the locations for PE were appropriate, but some teachers stated that more time should be devoted to PE, as they were concerned about the general levels of physical activity in children.

\section{PARTICIPATION IN LIGHT EXERCISE}

Overall, $57 \%$ of children were reported to engage in 20 minutes of light exercise at least three times a week, and there were no significant differences between the sexes. Other studies have reported minimal or no difference in moderate activity between boys and girls. ${ }^{14} 15$ Of concern is the lack of even moderate activity in $43 \%$ of the sample. Activities such as cycling and walking are important lifestyle activities that can help to prevent many diseases in adulthood. Formation of these lifestyle habits in childhood may influence activity patterns in adulthood. ${ }^{2}$ Of interest was the difference in the proportion of children in area 1 and areas 4 and 5 who walked to school-that is, comparing those of higher socioeconomic status with lower. Overall, 33\% of children were driven to school by car and 5\% went by bus. Some $40 \%$ walked, and $20 \%$ walked part of the way. These figures are in contrast with a previous study in 1990, in which $77 \%$ of primary schoolchildren were driven to school. ${ }^{7}$ It is not clear in the latter study whether some children were from rural areas that were too distant from school for walking.

TIME SPENT IN SEDENTARY OCCUPATIONS Watson ${ }^{17}$ reported that Irish children spend a mean of just under three hours a day watching television, and in the United States it has been reported that $67 \%$ of children watch television for at least two hours a day. ${ }^{9}$ The figure in this study of $77 \%$ spending at least two or three hours a day in front of a screen is higher, but includes the playing of computer games as well as watching television. This amount of time spent sedentary each day is of concern because it can be correlated to the amount of body fat. ${ }^{9}$ No differences were seen in energy expended in regular activity for those spending more or less than three hours a day in front of a screen, but the time spent sitting may be at the expense of unorganised spontaneous activity, which was not assessed in this study. Regular activities such as swimming, ballet, and rugby tend to be planned in advance, whereas television is watched at times when the child is free from school or organised activities. 
LIMITATIONS OF THE STUDY

One limitation of the study is that it uses subjective evaluation of the frequency and duration of activity by the parents, which could lead to an overestimation. We acknowledge that, whereas the questionnaire used was validated in teenagers, it was completed in this study by parents because of the relatively young age of the children studied. Return rates from areas of lower socioeconomic status were low compared with those from areas of higher socioeconomic status, which may have led to bias. Another limitation is that the questionnaire investigated regular physical activity and did not take into account non-organised play in the school yard, garden, park, etc. When children are playing outside, parents may be unaware of the amount of activity engaged in. It has also been documented that children of this age may not often participate in vigorous activity of $70 \%$ of maximum heart rate for 20 minutes or more in one session. Armstrong et $a l^{18}$ found that five minutes of intense activity, as measured by continuous heart rate monitoring in sixth year (primary) children, was common and that few children spent periods of 20 minutes or longer with heart rates above the recommended threshold (140 beats $/ \mathrm{min}$ ). Monitoring of heart rate would not have been feasible for a study involving nearly 800 subjects, and activities suggested under "hard exercise", such as basketball/football, were activities in which children of this age participated. It may be worth investigating heart rates achieved during a session of football/ basketball in this age group, as Armstrong et $a l^{18}$ did not relate heart rate findings to specific activities.

\section{CONCLUSION}

This study presents results on physical activity levels in a large sample of Dublin schoolchildren in the 7-9 year age group. Although direct comparisons with other studies are difficult because of the different methods used, many of the findings of this study are similar to those in many other published reports. Despite the limitation of the method of measuring regular activity, our data support findings of previous studies that boys participate in more physical activity than girls even at this young age. ${ }^{818} \mathrm{~A}$ worrying number ( $14 \%$ boys and $24 \%$ girls) are not performing the volume of physical activity necessary to benefit the cardiovascular system. However, the limitation of not assessing non-organised intermittent activity needs to be addressed, as this type of activity is natural in young children. Furthermore the influence of overall activity and fitness levels needs to be investigated.

1 Paffenbarger RS, Hyde RT, Wing AL, et al. Physical activity, all-cause mortality, and longevity of college alumni. N Engl 7 Med 1986;314:605-13.

2 Telma R, Leskinen E, Yang X. Stability of habitual physical activity and sports participation: a longitudinal tracking study. Scand $\mathcal{7}$ Med Sci Sports 1996;6:371-8.

3 Boreham CC, Twisk J, Savage MJ, et al. Physical activity, sports participation, and risk factors in adolescents. Med sports participation, and risk fact
Sci Sports Exerc 1997;29:788-93.

4 Davies PSW, Gregory J, White A. Physical activity and body fatness in pre-school children. Int f Obes 1995;19:6-10.

fatness in pre-school children. Int f Obes 1995;19:6-10.
American College of Sports Medicine. The recommended

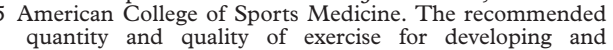
quantity and quality of exercise for developing and 1990;22:265-74

6 NIH Consensus Conference. Physical activity and cardiovascular health. $\mathcal{F A M A 1 9 9 6 ; 2 7 6 : 2 4 1 - 6 .}$

7 Watson AWS, Drummy VJ. Activity and lifestyle characteristics of Irish school children aged 10-13: a pilot study. COSPOIR report. Limerick: Brunswick Press Ltd, 1993.

8 The National Health and Lifestyle Surveys. Surveys of lifestyle, attitudes and nutrition (SLAN) and The Irish health behaviour in school aged children survey (HBSC) Galway: Department of Health and Children, National University of Ireland, 1999.

9 Andersen RE, Crespo CJ, Bartlett SJ, et al. Relationship of physical activity and television watching with body weight and level of fatness among children. $7 A M A$ 1998;279:93842 .

10 Saris WHM. Habitual physical activity in children: methodology and findings in health and disease. Med Sci Sports ology and findings in

11 SAHRU technical report No 2: a national deprivation index for health and health services research. Dublin: Department of Community Health and General Practice, Trinity College, 1997.

12 Aaron DJ, Kriska AM, Dearwater SR, et al. Reproducibility and validity of an epidemiologic questionnaire to assess past year physical activity in adolescents. Am f Epidemiol 1995;142:191-201.

13 Montoye HJ, Kemper CG, Saris WHM, et al. Measuring physical activity and energy expenditure. 2nd ed. Champaign, IL: Human Kinetics, 1996.

14 Armstrong N, Bray S. Physical activity patterns defined by continuous heart rate monitoring. Arch Dis Child 1991;66: $245-7$.

15 Falgairette G, Gavarry O, Bernard T, et al. Evaluation of habitual physical activity from a week's heart rate monitoring in French school children. Eur f Appl Physiol 1996;74: ing in Fren

16 Riddoch CJ, Boreham CA. The health related physical activity of children. Sports Med 1995;19:86-102.

17 Watson A. Height, body weight, skinfold thickness and endurance fitness of children attending national schools in Ireland. Ir f Med Sci 1993;162:358-61.

8 Armstrong N, Balding J, Gentle P, et al. Patterns of physical activity among 11 to 16 year old British children. BMF 1990;301:203-5.

\section{Take home message}

In a group of 7-9 year old Irish children, boys were found to be more active than girls, nearly a quarter of whom are performing less than the volume of activity recommended for cardiovascular benefits. Of particular concern is the time spent in sedentary occupations and the lack of participation in even light to moderate activity such as walking and cycling. 


\section{Commentary}

It is becoming increasingly clear just how inactive children are nowadays. This paper confirms in Irish children what previous studies have indicated in Ireland, elsewhere in Europe, in North America and, to a lesser extent in South-East Asia, and the antipodes. It shows the impact television and computer games are having everywhere, and, by differentiating periods of low levels of activity interspersed with spans of more vigorous activity, it draws special attention to the care we need to have in describing children's activity. Social factors are important in determining disease, so it should come as no surprise to find it influencing childhood behaviour too. The authors have performed a service in opening this aspect, but they have found it difficult to obtain quite what may be required if policy is to be developed to rectify it. Do not seek here the solutions to this problem affecting so many parts of the world, but do ensure that the opinion leaders know that, so far, no nation seems immune from this creeping physical inactivity.

BRIAN KIRBY

Children's Health $\mathcal{E}$ Exercise Research Centre, University of Exeter

\section{Commentary}

The case for physical activity and health in children is widely accepted and promoted by health authorities, ${ }^{1}$ but is set against a background of rapidly increasing levels of obesity ${ }^{2}$ for which increasingly sedentary lifestyles are largely responsible. ${ }^{3}$

Characterising and measuring children's activity has proved to be far from easy, as at least five dimensions of activity can impact on different aspects of health. ${ }^{4}$ This study highlights both the worrying trend towards inactivity in children, and the problems of reliably recording overall activity in this young age group by user friendly questionnaire. Accelerometers show promise in measuring activity patterns in children, but have not yet been fully validated, and are currently too expensive to be widely used as a large scale research tool. However, as safety concerns place more restrictions on children's leisure activities, and they are wooed by ever increasing options for sitting in front of various types of screen for entertainment, accurate measurement of activity patterns is essential to find out which children are at risk and why, and to enable effective interventions in making them more active.

DAVID WATKINS

1 Health Education Authority. Young and active: draft policy framework for young people and health-enhancing physical activity. London: Health Education Authority, 1997.

2 Chinn S, Rona RJ. Prevalence and trends in overweight and obesity in three cross sectional studies of British children, $1974-94$. BMF 2001;322:24-6.

3 Prentice AM, Jebb SA. Obesity in Britain: gluttony or sloth? BMF 1995;311:437-9.

4 Fox KR, Riddoch C. Charting the physical activity patterns of contemporary children and adolescents. Proc Nutr Soc 2000;59: 497-504

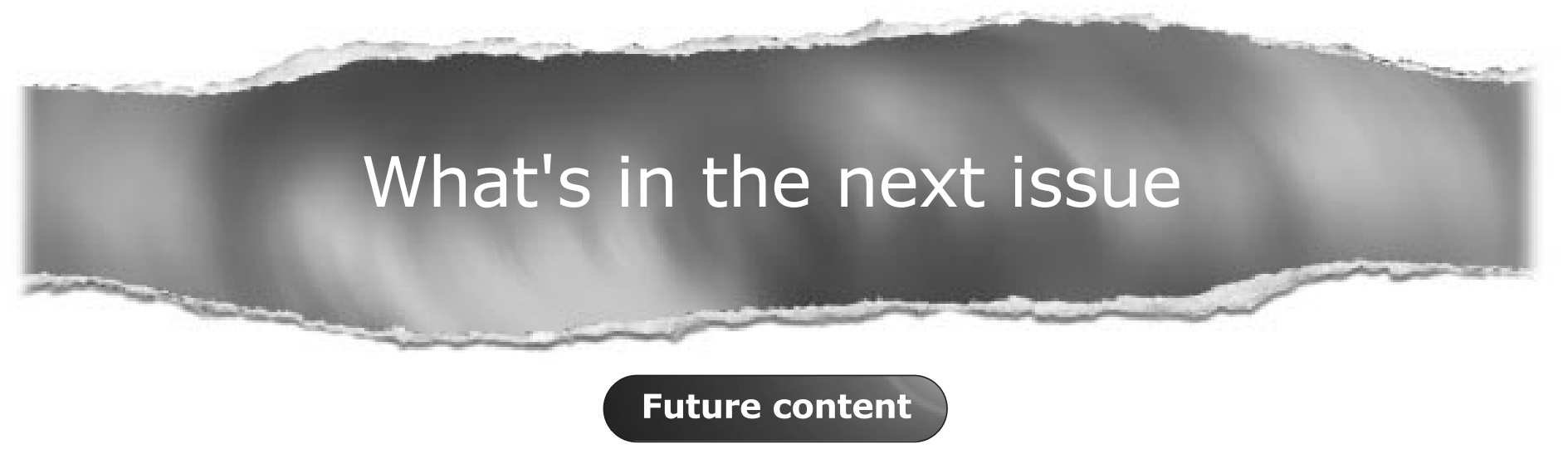

See which articles have just been accepted for publication and preview the table of contents for the next issue a month before it is published

\section{www.bjsportmed.com}

